\title{
Correction to: A Critical Review of Students' and Teachers' Understandings of Nature of Science
}

\author{
Hernán Cofré ${ }^{1,2}$ (D) Paola Núñez ${ }^{1,2} \cdot$ David Santibáñez $^{3} \cdot$ José M. Pavez ${ }^{4}$. \\ Martina Valencia $^{2} \cdot$ Claudia Vergara $^{5}$
}

Published online: 5 July 2019

(C) Springer Nature B.V. 2019

\section{Correction to: Science \& Education (2019) 28:205-248 https://doi.org/10.1007/s11191-019-00051-3}

The original article unfortunately contains incorrect presentation of Tables 1, 3, 4, 5 and 6.

The correct presentation of Tables 1, 3, 4, 5 and 6 are shown below.

The online version of the original article can be found at https://doi.org/10.1007/s11191-019-00051-3

Hernán Cofré

hernan.cofre@pucv.cl

1 Instituto de Biología, Facultad de Ciencias, Pontificia Universidad Católica de Valparaíso, Av.

Universidad 330, Curauma, Valparaíso, Chile

2 Magister en Didáctica de las Ciencias Experimentales, Facultad de Ciencias, Pontificia Universidad Católica de Valparaíso, Valparaíso, Chile

3 Facultad de Educación, Universidad Católica Silva Henríquez, Santiago, Chile

4 Department of Math and Science Education, College of Education, University of Georgia, Athens, USA

5 Facultad de Filosofia y Humanidades, Universidad Alberto Hurtado, Santiago, Chile 


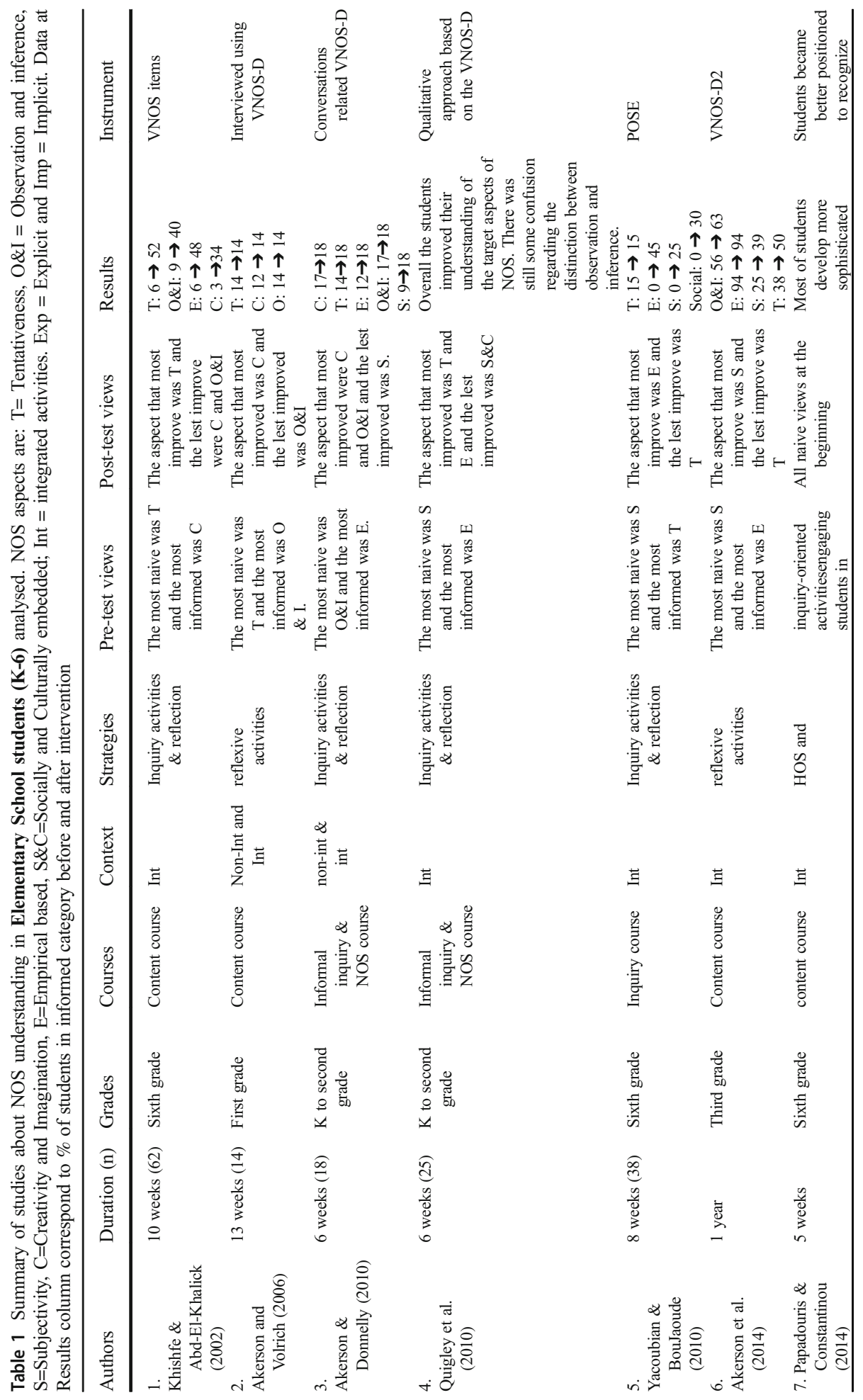




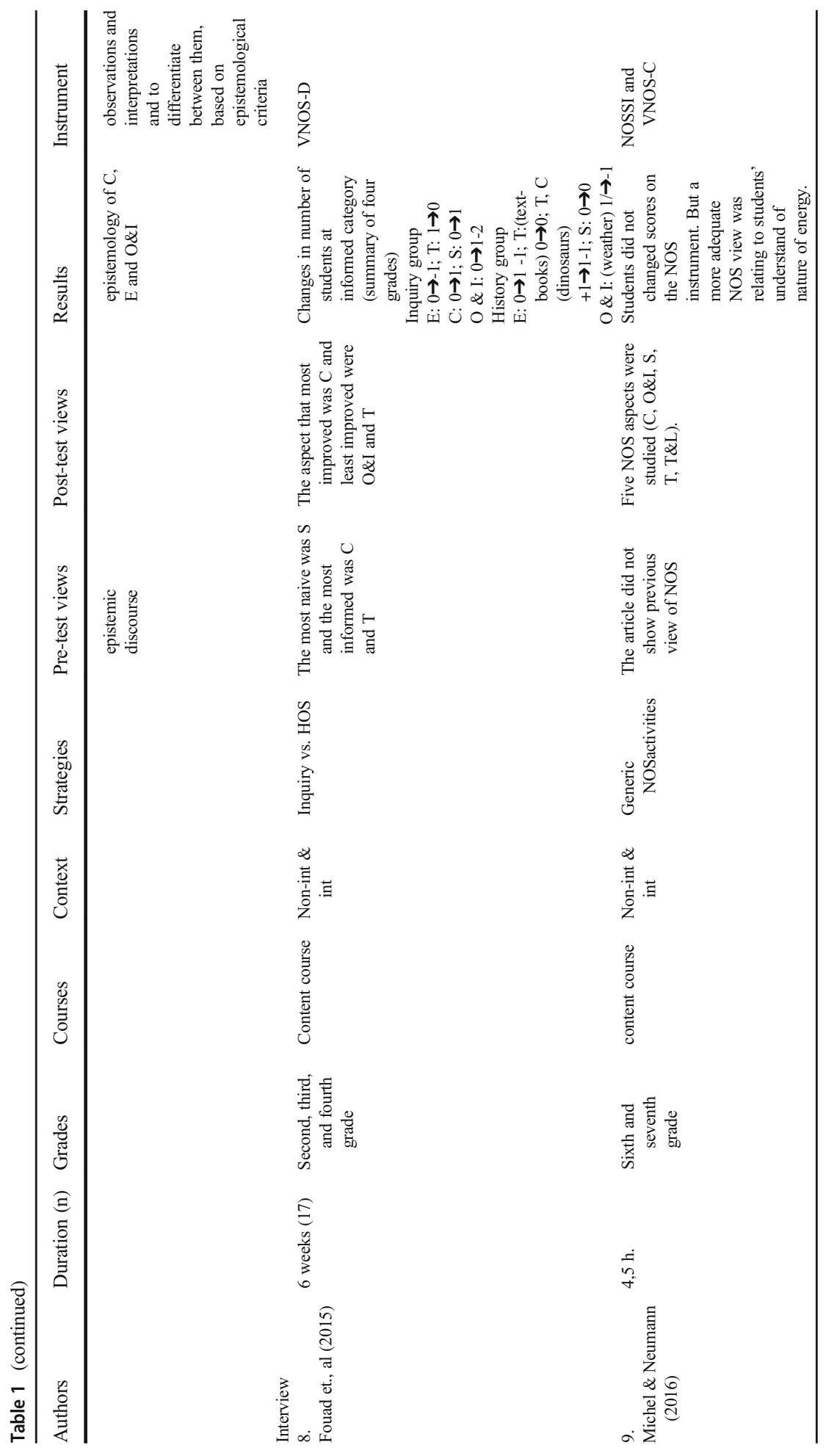




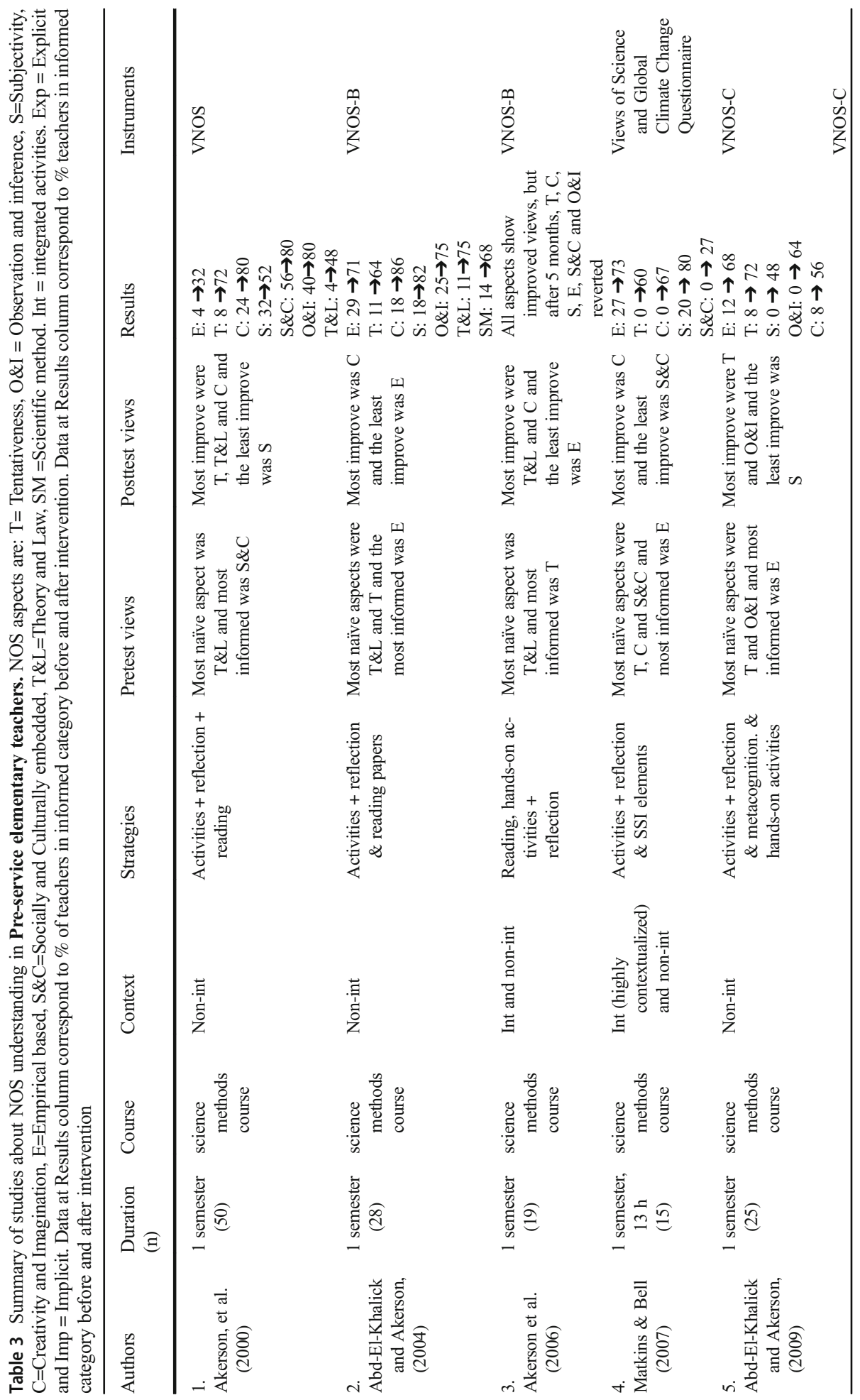




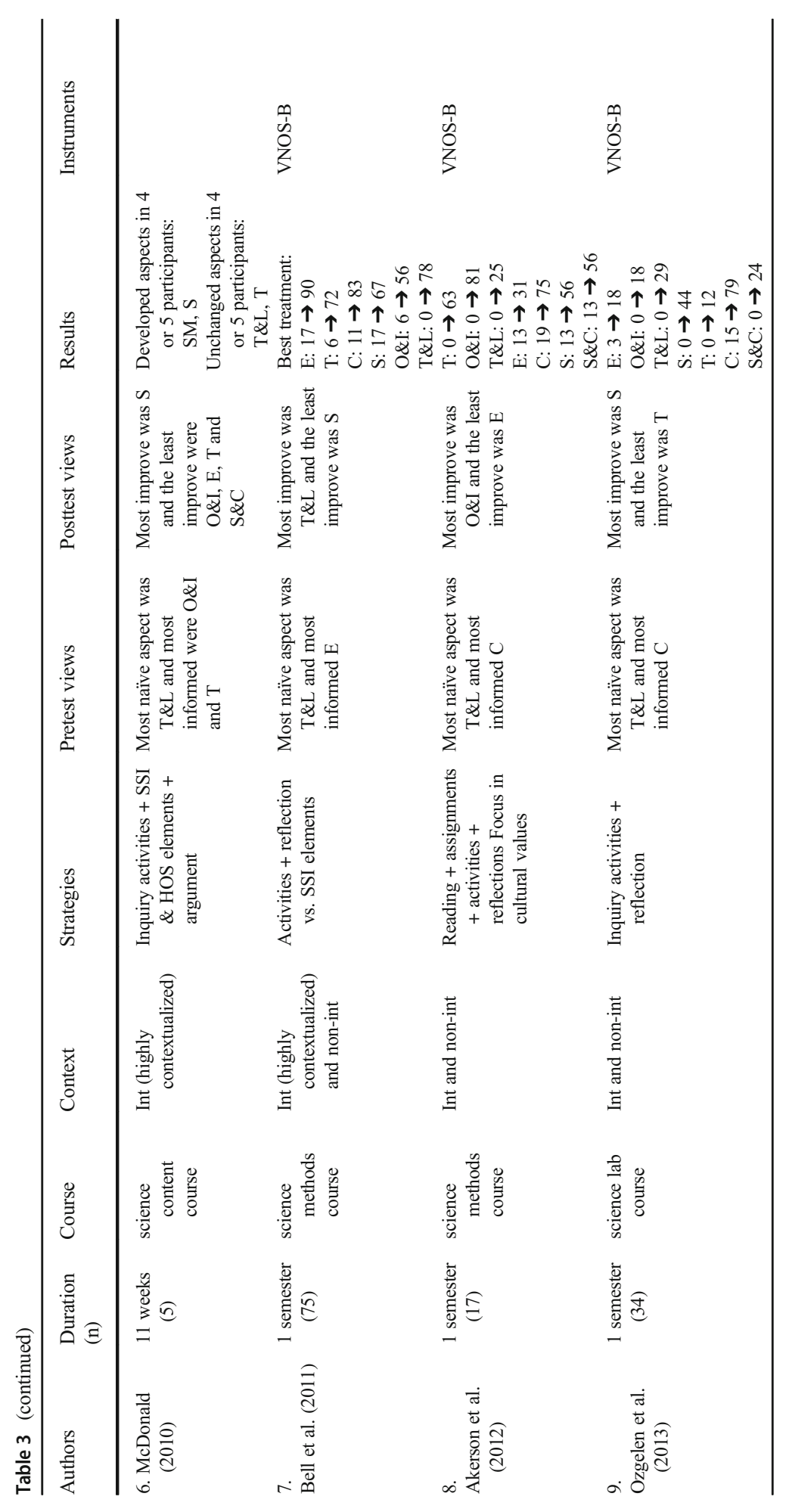



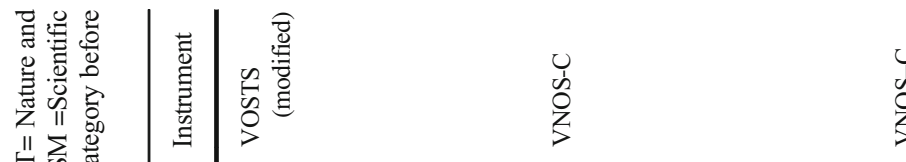

0
1
0
0
$\vdots$
3

$\stackrel{5}{5}$

II $\sum_{\text {i }}$

实

突

롤 ह

궁젱

焉焉

光它

合

可

元

远

III 娄言

运

记

究 言

至至

चु हี

空

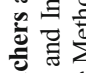

Ð

跣

记

的

过

递兽

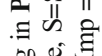

春苛

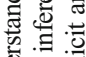

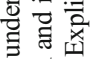

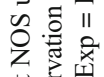

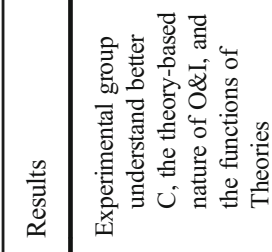

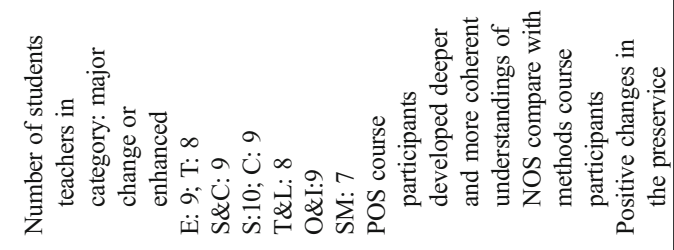

$\infty$ 苞高

象

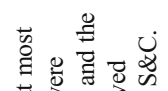

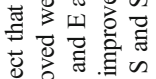

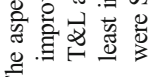

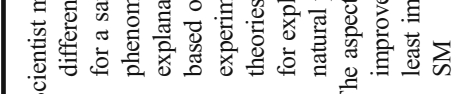

F

离疎

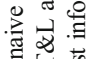



क्ष

节

若

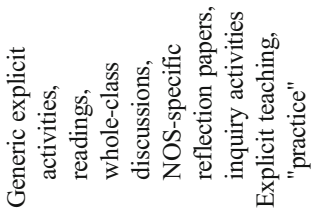

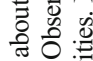

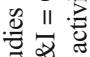

尊焉

पे

范 吾

言莒苔.声

จ. 몽



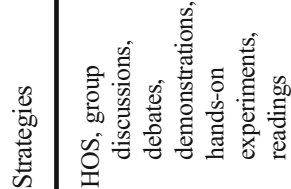



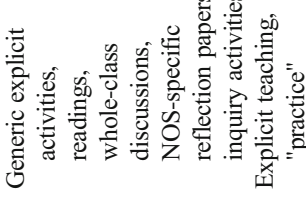



(2)

(2)

总。

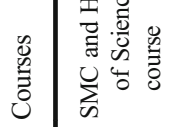

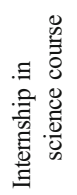

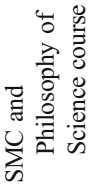

$\hat{2}$
$\frac{n}{0}$
$\vdots$
0

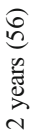

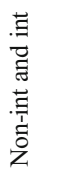

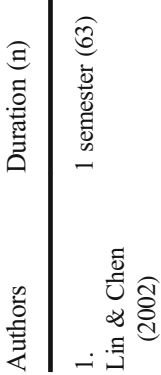

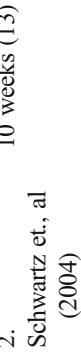

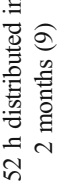














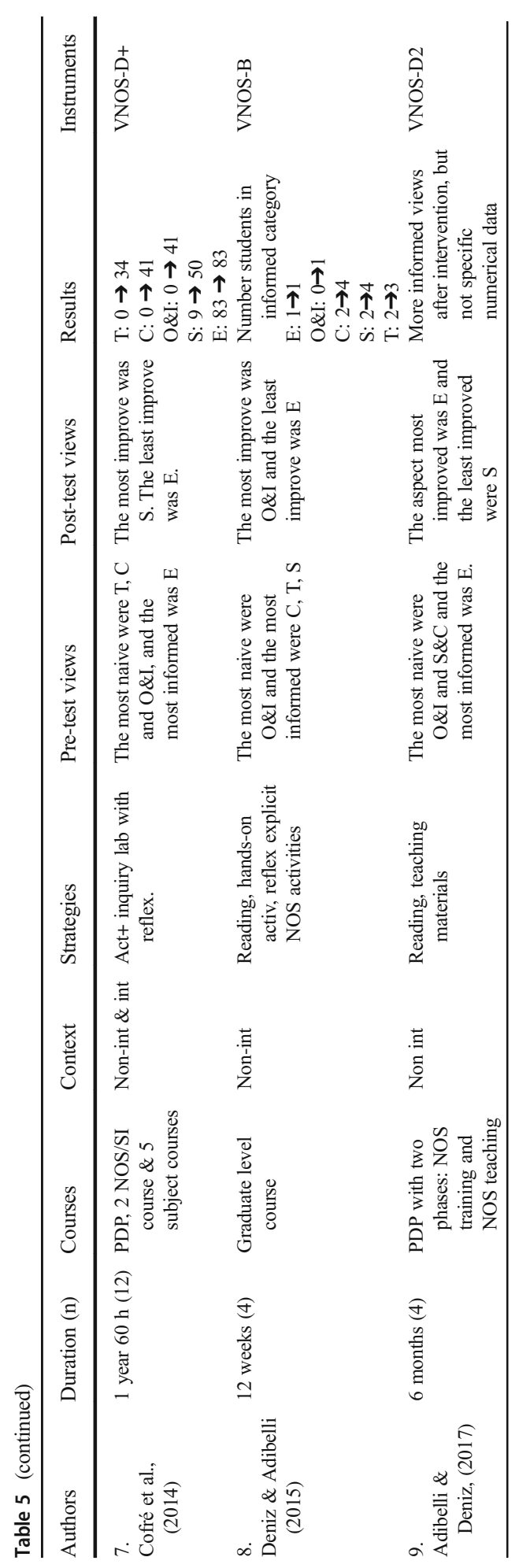




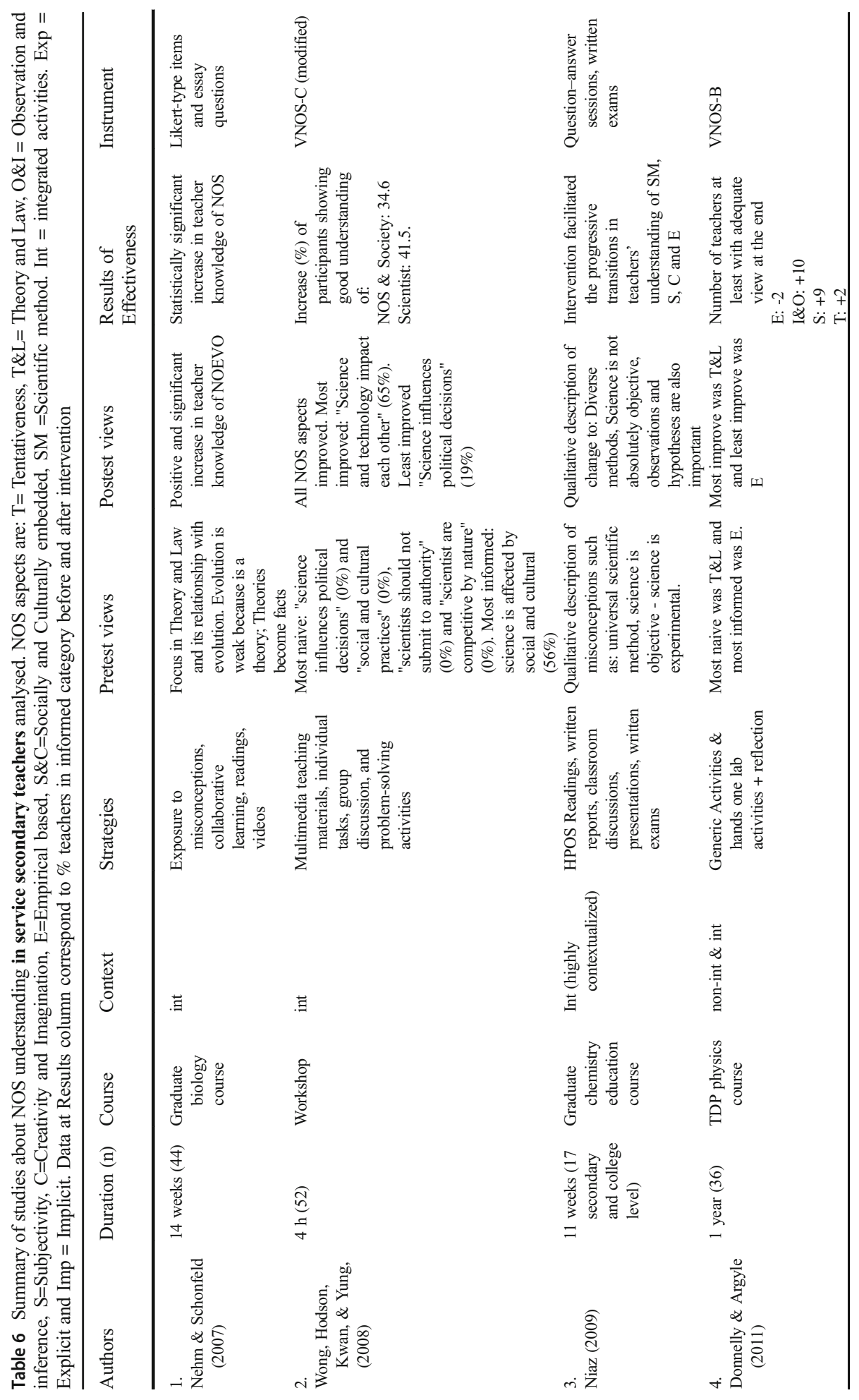




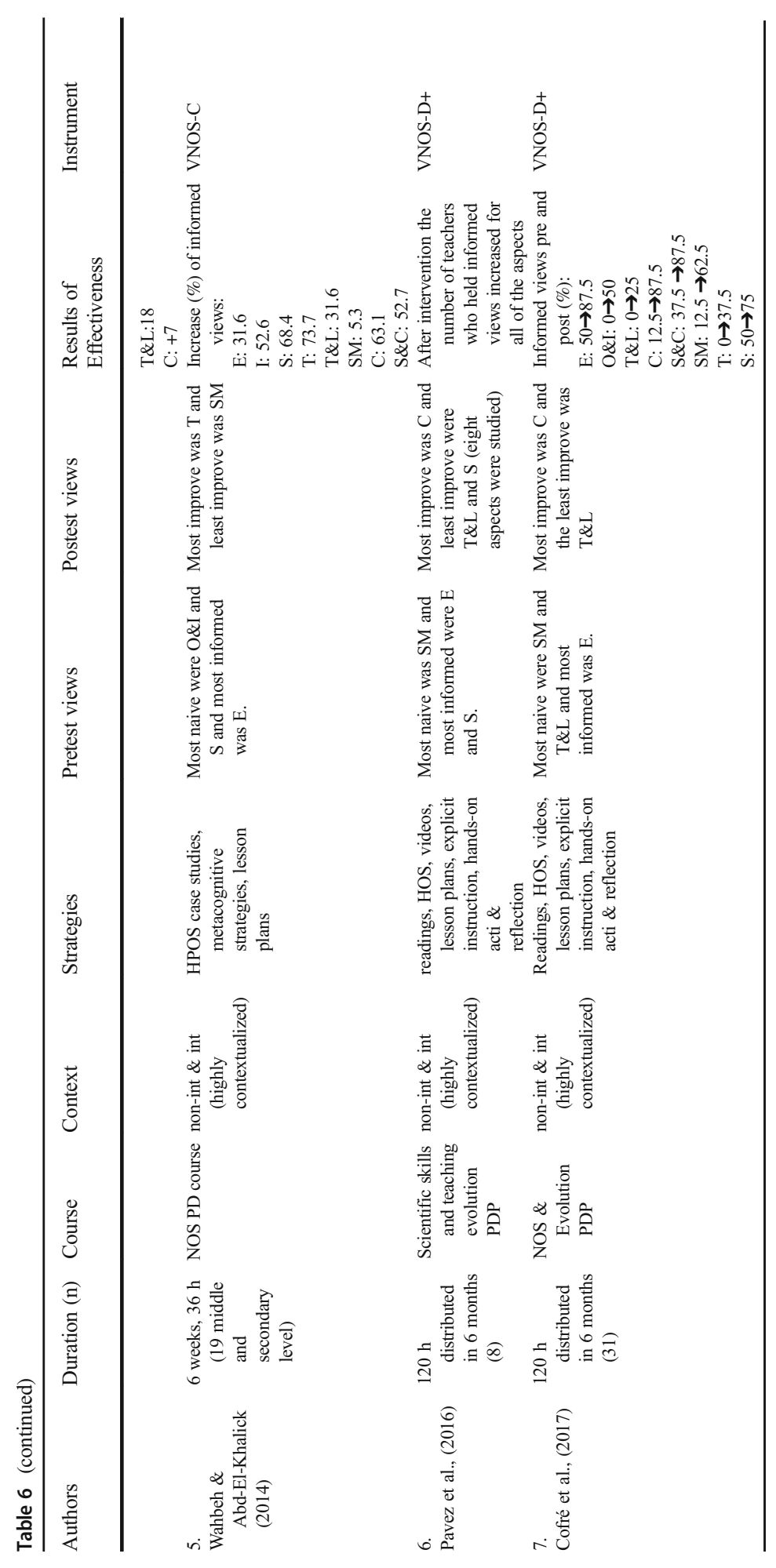


Publisher's Note Springer Nature remains neutral with regard to jurisdictional claims in published maps and institutional affiliations. 